\title{
Commentary
}

\section{Sugar as a slimming agent?}

Does dietary composition in itself have any importance for weight gain and obesity? Meta-analyses of dietary intervention trials comparing ad libitum normal-fat diets with low-fat diets clearly demonstrate that a reduction in the dietary fat content decreases body fat stores (Bray \& Popkin, 1998; Yu-Poth et al. 1999; Astrup et al. 2000). Energy from fat has a weaker satiating power than energy from carbohydrates, and individuals are unconsciously more likely to consume more energy from fat-rich diets than from carbohydrate-rich diets. In addition, there also seems to be important differences in the digestion and metabolism of fat and carbohydrates which may influence energy balance.

In order to gain a better understanding of the effects of fat and carbohydrate on energy metabolism, it is necessary to eliminate the effect of appetite regulation and induce overeating in paid experimental subjects. This is a method used by Lammert et al. (2000), who studied the response to overfeeding for $21 \mathrm{~d}$ with $5 \mathrm{MJ} / \mathrm{d}$ of either a fat-rich or an extremely-carbohydrate- and sugar-rich diet. Previous overfeeding studies using extreme carbohydrate-rich lowfat diets have shown that the conversion of the glucose to fat by the de novo lipogenesis does not occur before most of the oxidation of the body is covered by glucose, and the glycogen stores are filled. The conversion of glucose to fat is however energetically a very costly synthesis, and based on the stoichiometry it can be predicted that overfeeding with carbohydrate should result in a $21 \%$ lower fat deposition than overfeeding with an isoenergetic amount of fat (Flatt, 1992). Consequently, it should be less fattening to overeat carbohydrates than fat. This is exactly what Lammert et al. (2000) have tested. However, they do not think that they have revealed any differences between fat and carbohydrate overfeeding, but they overlook the main findings: overfeeding by carbohydrate compared with fat showed a mean net conversion of carbohydrate to fat of $15.8 \mathrm{~g} / \mathrm{d}$ in contrast to $0 \mathrm{~g} / \mathrm{d}$ on fat overfeeding. This $d e$ novo lipogenesis was estimated to account for $40 \%$ of the increase in fat mass about $332 \mathrm{~g}$ fat. In addition they found a $30 \%$ higher faecal energy loss equivalent to $8 \mathrm{MJ}$ during the $21 \mathrm{~d}$. These increased energy outputs should be expected to result in a lower fat deposition on the carbohydrate overfeeding and actually they do find a 30 $\%$ lower increase in fat mass despite an $18 \%$ higher energy intake during the carbohydrate-overfeeding regimen. The subjects should therefore eat $68 \%$ more energy in order to increase body fat stores by $1 \mathrm{~kg}$ on carbohydrate overfeeding than on fat overfeeding (155 MJ $/ \mathrm{kg} v .42 \mathrm{MJ} / \mathrm{kg}$ ). This difference was not significant, but the study does not possess the sufficient statistical power to demonstrate a difference of such magnitude. As can also be seen from the study, overfeeding of non-related individuals results in substantial differences in body-fat gain, which can be attributed to genetic variation in the ability (to increase energy expenditure; Bouchard et al. 1990; Levine et al. 1999). When the study was designed, a power calculation would have shown, that a statistically significant difference of $20 \%$ in fat gain would have required at least twice as many subjects. Alternatively a cross-over design or identical twins could have been used. The authors do not comment on this point and one may assume that the lack of significance of the $68 \%$ higher energy cost of fat deposition on the carbohydrate overfeeding is due to a type 2 error.

Is it then correct when Lammert et al. (2000) conclude that they do not find any evidence for increased thermogenesis during carbohydrate overfeeding? No, an assessment of the energy balance on the two overfeeding regimens speaks for itself (Fig. 1). The extra energy intake is $5.6 \mathrm{MJ} / \mathrm{d}$ over 21 d, i.e. $118 \mathrm{MJ}$, of which $8.6 \%$ is lost as faecal energy. Gain of fat mass and fat-free mass can at best explain $34 \mathrm{MJ} / \mathrm{kg}$ for $1.36 \mathrm{~kg}$, i.e. $46 \mathrm{MJ}$ (Forbes et al. 1986). The additional energetic cost of de novo lipogenesis of $332 \mathrm{~g}$ fat can explain an additional $4 \mathrm{MJ}$, but where is the remaining $118-(9+46+4)$ MJ, i.e. $59 \mathrm{MJ}$ or $50 \%$ of the energy intake during the overfeeding? The authors overlook the possibility of increased thermogenesis (luxury consumption) during day and evening time, when the experimental subjects were awake (Levine et al. 1999). Unfortunately, energy expenditure was only measured at night time. Two alternatives should also be considered:

1. The subjects did not consume all the food or have vomited. The authors need to be able to exclude this possibility;

2. A contributory explanation is that the amount of energy overfed is overestimated. The experimental subjects' habitual energy requirements were estimated based on self-reported food intake before the trial. The energy intake during the overfeeding was equal to habitual self-reported energy intake $+5 \mathrm{MJ} / \mathrm{d}$. As it is well known that under-reporting is a major problem in self-reported energy intake, it is most likely that the energy requirements for weight maintenance was roughly underestimated, which may explain why the subjects gained much less weight than expected during the overfeeding. Thus, a substantial part of the unexplained faith in the excess energy intake was actually used to cover the subjects' basic individual requirements. This error, however, would be similar 
Fat overfeeding

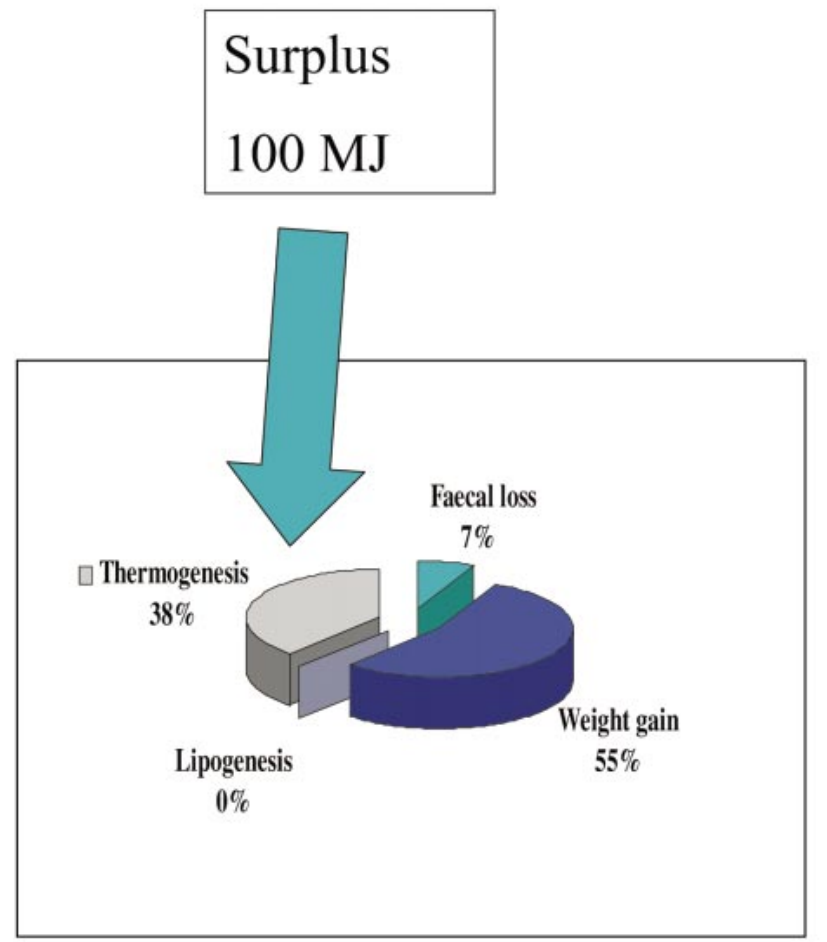

\section{$\mathrm{CHO}$ overfeeding}

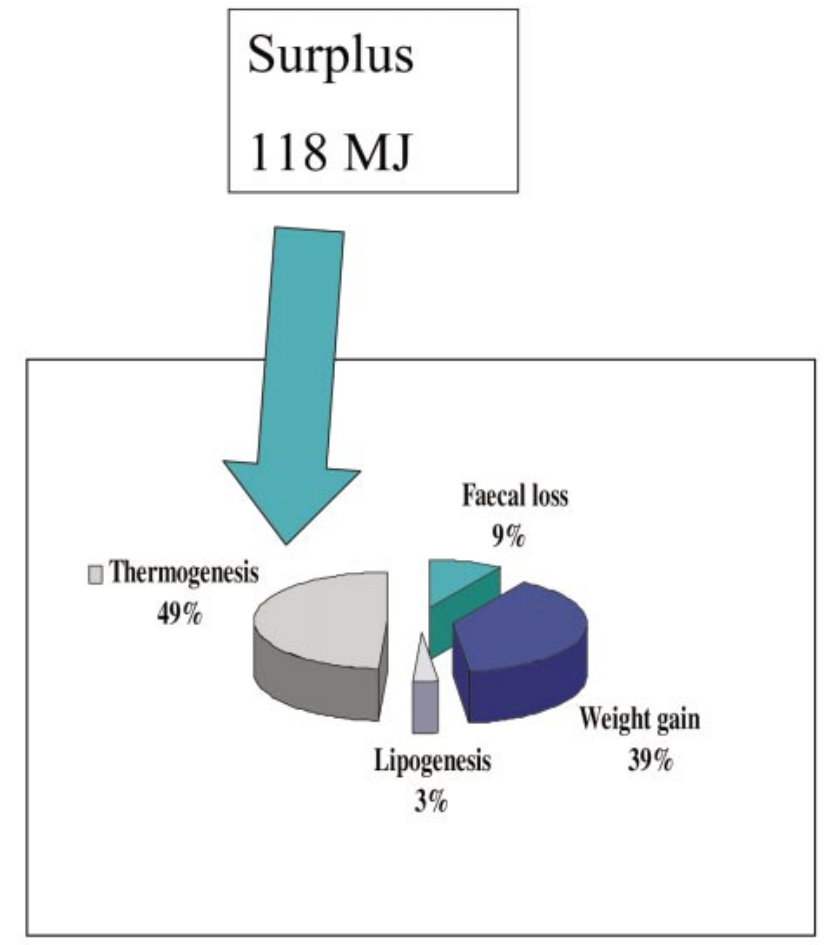

$68 \%$ more energy were required to gain $1 \mathrm{~kg}$ body fat on $\mathrm{CHO}$ than on fat overfeeding $(155 \mathrm{MJ} / \mathrm{kg} v .42 \mathrm{MJ} / \mathrm{kg})$

Fig. 1. Energy balance on two overfeeding regimens: a fat-rich diet and an extremely-carbohydrate(CHO)-rich diet.

during carbohydrate as well as fat overfeeding, and any difference in metabolic efficiency between these two regimens, would therefore rather be explained by differences in thermogenesis.

In conclusion, carbohydrate overfeeding with ' $15-30 \%$ purified sucrose' as the authors have expressed it, in comparison with fat overfeeding led to a greater faecal energy loss and increased energy loss due to de novo lipogenesis. An assessment of the energy balance on the overfeeding demonstrates that, in spite of massive overfeeding, it is difficult to increase fat mass in normal-weight subjects, particularly on carbohydrate overfeeding, most likely because other energy combusting mechanisms are activated.

There will probably be substantial public interest in this study, and it is our hope that the authors in their communication of the result will recognise our analysis and derived conclusions. In order to provide a coherent picture, the weaknesses and limitations of the study should be brought together with newer studies which have clearly shown that the mechanisms responsible for an increased energy expenditure are activated during overfeeding. An indepth understanding of this topic can become very important in the preventive treatment of obesity.
Arne Astrup and Anne Raben

Research Department of Human Nutrition The Royal Veterinary and Agricultural University

Rolighedsvej 30

1958 Frederiksberg C.

Denmark

Tel: +4535282476

Fax: +4535282483

Email: ast@kvl.dk

\section{References}

Astrup A, Ryan L, Grunwald G, Storgaard M, Saris W \& Hill JO (2000) Ad libitum low-fat diets and body fatness: A metaanalysis of intervention studies. British Journal of Nutrition 83, S25-S32.

Bouchard C, Tremblay A, Despres JP, Nadeau A, Lupien PJ, Theriault G, Dussault J, Moorjani S, Pinault S \& Fournier G (1990) The response to long-term overfeeding in identical twins. New England Journal of Medicine 322, 1477-1482.

Bray GA \& Popkin BM (1998) Dietary fat intake does affect obesity. American Journal of Clinical Nutrition 68, 1157-1173.

Flatt JP (1992) Energy Costs of ATP Synthesis. In Energy Metabolism: Tissue Determinants and Cellular Corollaries, pp. 
319-343 [JM Kinney and HN Tucker, editors]. New York: Raven Press Ltd.

Forbes GB, Brown MR, Welle SL \& Lipinski BA (1986) Deliberate overfeeding in women and men: energy cost and composition of the weight gain. British Journal of Nutrition $\mathbf{5 6}$, $1-9$.

Lammert O, Grunnet N, Faber P, Bjørnsboe KS, Dich J \& Larsen LO (2000) Effects of isocaloric overfeeding of either carbohydrate or fat in young men. British Journal of Nutrition 84, 233 245.
Levine JA, Eberhardt NL \& Jensen MD (1999) Role of nonexercise activity thermogenesis in resistance to fat gain in humans. Science 283, 212-214.

Yu-Poth S, Zhao G, Etherton T, Naglak M, Jonnalagadda S \& Kris-Etherton PM (1999) Effects of the National Cholesterol Education Program's step I and step II dietary intervention programs on cardiovascular disease risk factors: A metaanalysis. American Journal of Clinical Nutrition 69, 632-646. 